\title{
SIMULATION OPTIMIZATION IN DOSING PROCESS CONTROL SYSTEM IN REAL TIME IN A FREE AND OPEN-SOURCE SOFTWARE
}

\author{
Gustavo Rodrigues Fraga, Túlio Almeida Peixoto \\ and Joao Jose de Assis Rangel*
}

Received August 22, 2017 / Accepted April 6, 2018

\begin{abstract}
The purpose of this work is to implement an on-line control system able to adjust the production in real time applying a simulation model with algorithmic optimization and data transfer for a programmable logic controller. The Solver tool of the Excel software was integrated into a simulation software used to find the optimal dosing of input aggregates in a Hot Mix Asphalt process. Tests were carried out in different scenarios; the results demonstrated that the proposed control was effective, leading to a possible improvement in the quality of the product, enabling it to be kept within the specifications desired for most of the time. Besides, the proposed solution appeared to be simple and accessible for small companies as it applies the Excel software and a free and open-source discrete event simulation software.
\end{abstract}

Keywords: Real time optimization, Simulation, PLC, Excel, Industry 4.0.

\section{INTRODUCTION}

In a work about simulation optimization in the Industry 4.0 era, Xu et al. (2016) mentioned that a new era of industrialization has emerged. The increase in productivity has been the focus of all previous industrial revolutions, starting with the invention of the steam engine in the first Industrial Revolution, continuing with the Taylorism, automation, and computerizing, driven by the production industries themselves. According to Oesterreich (2016) and Schuh (2015), the term Industry 4.0 comprises various technologies that allow the development of automated and digital manufacturing.

Therefore, modeling and simulation have been described as a relevant concept for managing the increase in complexity of manufacturing processes, assisting, thus, their improvement. Since its creation, the simulation has been applied to various sectors such as manufacturing, services, health, logistics among others (Jahangirian, 2010). Simulation is traditionally used as a tool of

*Corresponding author.

Universidade Candido Mendes (UCAM-Campos), 28030-335 Campos dos Goytacazes, RJ, Brasil.

E-mails: gustavo.r.fraga@gmail.com; tulioap@gmail.com; joao.rangel@ucam-campos.br 
analysis to predict the effect of changes in existing systems or to help estimate the performance of projects in the design phase.

In the pursuit of the highest productivity, these changes in the system have to be more and more accurate, seeking the highest performance of it. For this reason, the simulation can be employed together with optimization techniques, which search for improved configurations of the system with respect to the performance measurement. Usually, algorithms that are used to search for consecutive approximations in pursuit of the best solution are applied. The most used algorithms are gradient-based, random search algorithms, evolutionary algorithms, mathematical programmingbased approaches and statistical search techniques (Fu et al., 2000). These algorithms can execute modifications in the process in real time. The simulation optimization in real time allows the process to continuously adapt to the disruptions and variations in the input, keeping the quality and requirements of the final product throughout the process.

According to what was exposed, the objective of this work is to implement and test the integration between a discrete event simulation software, a Programmable Logic Controller (PLC), and optimization in real time. The main issue of the work is the combined solution of the possibility of optimizing a process applying the Solver of Microsoft ${ }^{\circledR}$ Excel ${ }^{\circledR}$ software and the simulation model, which can also actuate in a control system in real time. That is, the optimization searches for the optimal point of adjustment of the process that can be tested with the simulation model and that can also communicate at the same time with the control system of the process.

\section{PROBLEM DEFINITION}

The continuous search for the improvement of the processes in the Industry 4.0 era and the growth of automated systems have caused an increase in the efficiency of the control systems in real time of the process to guarantee the final product quality. This standardization in the product specifications increases the productivity and reduces different types of costs inherent to the processes, improving the results for the companies.

Dosing processes are used in several industrial applications, such as pharmaceuticals, chemicals, food industries, and civil construction. In these kinds of processes, each manufacturing step contributes significantly to the final quality of the product. Thus, a strict control of all production process is necessary so that the quality specifications of the final product are met (Imole et al., 2016). The correct dosing of soluble powder in the beverage manufacturing process, for example, is the first step to guarantee a final quality product (Imole et al., 2016). In the Hot Mix Asphalt (HMA) production, approached in this work, the aggregate corresponds approximately to $95 \%$ of the weight of the asphalt concrete, while the asphalt binder, the 5\% left (Christensen, 2010). Therefore, the dosing of these input aggregates has an expressive importance in the quality control of this product.

The common practice of quality control in the asphalt industry uses offline methods. The sample is removed from the production process and sent to laboratory analysis to verify if the characteristics of the product are in accordance with the Job Mix Formula (JMF). Usually, the result of 
this analysis takes approximately two hours to complete. If the result presents a problem with the product, an operator must take corrective actions. However, this delay generates a product with low quality and several inherent costs. Considering that a typical process of asphalt production has a production rate of 300 tons/hour, this method of offline quality control can generate a waste of about 600 tons of material (Kabadurmus et al., 2010), or this product of poor quality may be used in roads and, in a short time, deteriorates. Figure 1 demonstrates the typical flow of analyses of Hot Mix Asphalt processes.

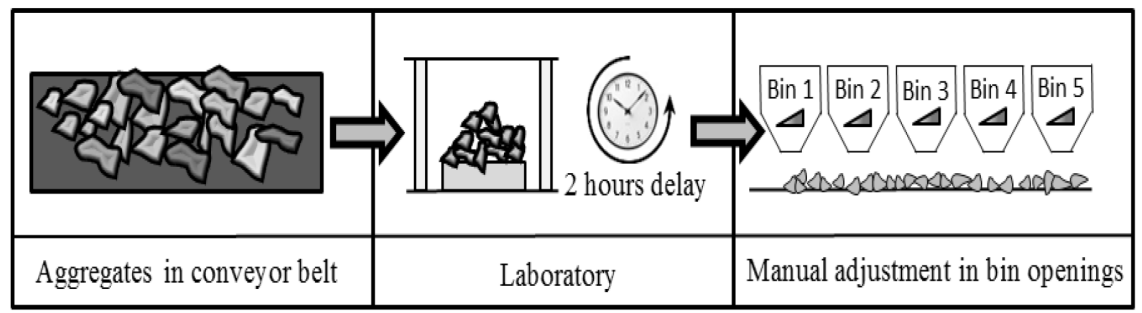

Figure 1 - Typical flow of analyses of Hot Mix Asphalt processes.

In the same way, other processes similar to the one presented in Figure 1 can be found in various industrial plants. Therefore, the improvement solutions for this process can be applied to other similar systems.

\section{CONTROL SYSTEM IN REAL TIME}

Some authors, such as Kabadurmus et al. (2010) and Zhang et al. (2014), have presented a new method of process control so that the long laboratory analysis time is minimized, and corrective actions are taken faster if necessary. In this approach, analysis techniques by images are applied in the real process. On the conveyor belt, images of the aggregates are taken continuously while an algorithm estimates the gradation of those aggregates.

A Discrete Event Simulation (DES) simulates the gradation values of the aggregates in the system used in this work. These values are sent to a spreadsheet (explained in subsequent sections), in which the optimal proportion of the combination of aggregates is calculated. The PLC receives these values and sends input and output signal of bins, as described in to Figure 2. Thus, a process control in real time can be carried out, continuously monitoring the process parameter to be controlled and acting correctively, when necessary, in the actuators that modify the process characteristics.

It can be noticed, in the area highlighted in Figure 2, that a DES software can simulate the values of gradation of those aggregates. The simulation of these values allows running tests in different scenarios giving more flexibility to the system.

Figure 3 presents in details how the integration of physical system with Excel solver is carried out. Notice that, firstly, the values of control limits, trend functions of aggregates and percentages of Bin openings are read from an Excel file. Then, the simulation model initiates and, at this point, 


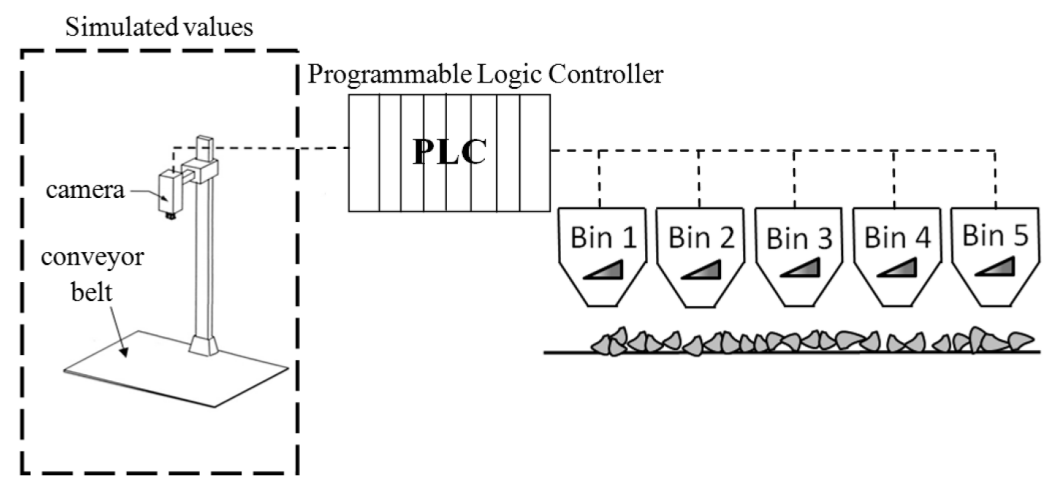

Figure 2 - Setup of the image analysis control system.

the trend function begins to work. These functions are essential tools for simulation, as they help the computational environment simulate the conditions of the real world. The Normal curve was used in the process, with determined values of mean and pattern deviation.

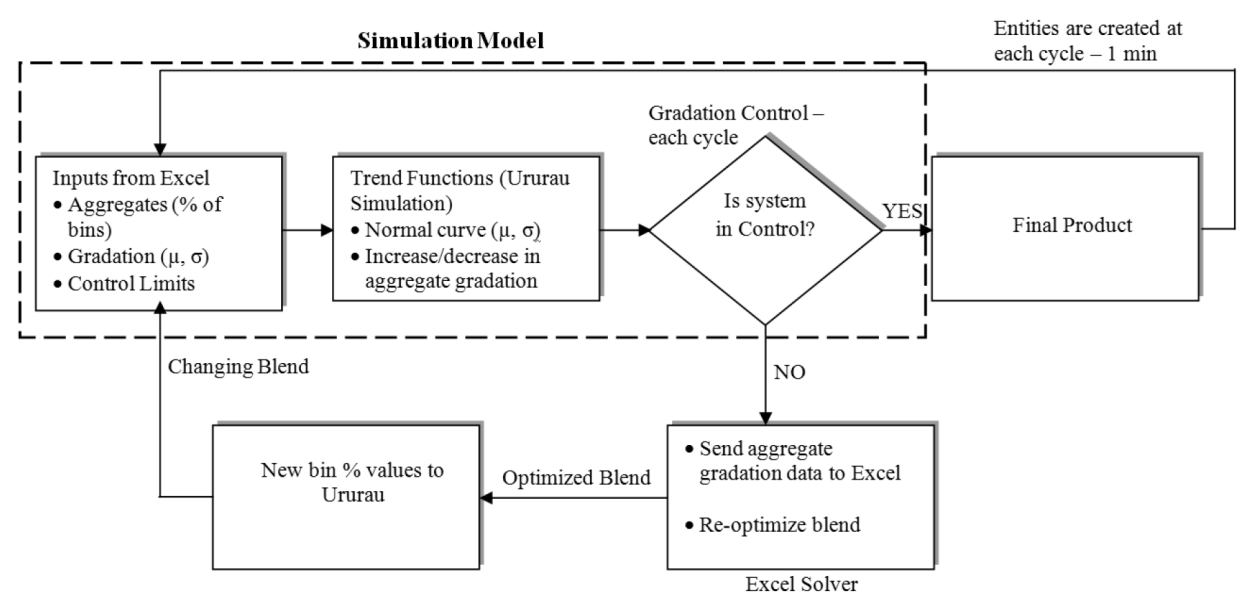

Figure 3 - Integration of physical system with Excel solver.

During the operation, the system continuously verifies if it is under control. We assume a system out of control when the granulation of one of the sieves is out of specification limits of the JMF. As the entities are created, according to the interval of time of discretization, it is also verified if the final product is in the control parameters according to this pre-defined time. The time interval in which the entities are created in this simulation was of 1 minute.

If the block of the final product is within the parameters of the process control, then it is not necessary to change the mixture. However, if the final product is out of specifications, corrective actions are taken. These actions are considered as changes in the opening percentages of the aggregate bins in order to reoptimize the mixture. 
As opening for the optimization system, the current granulation values of each sieve are read from Ururau and written in Excel. After the optimization model reoptimizes the mixture by giving new percentage values to the aggregates, these values are read from Excel and written back to Ururau, and the simulation continues with the new values of the mixture. The simulation continues until it gets the value of ten hours, which means one day of production.

\section{INTEGRATION OF SIMULATION MODEL WITH PLC AND EXCEL}

The Ururau software was design to have the capacity to exchange information with PLCs and Excel software. This interaction allows a greater flexibility within the system; it may use the simulation to assist in the testing of other systems. Therefore, Ururau exchanges information with Excel applying the Java API (Application Programming Interface) Apache POI, which operates various file formats based on Office Open XML and Microsoft's OLE 2 Compound Document format (OLE2) patterns.

Note, in Figure 4, that the Worksheet communicates directly with Ururau software, using "Read/Write" block, which can store Excel information such as internal Ururau variables. This simulation software is also able to run VBA macros in Worksheet. All Information in the Excel can be sent to the PLC by using the Assign block, which applies the OPC Interface to alter the values in Tag Database of PLC.

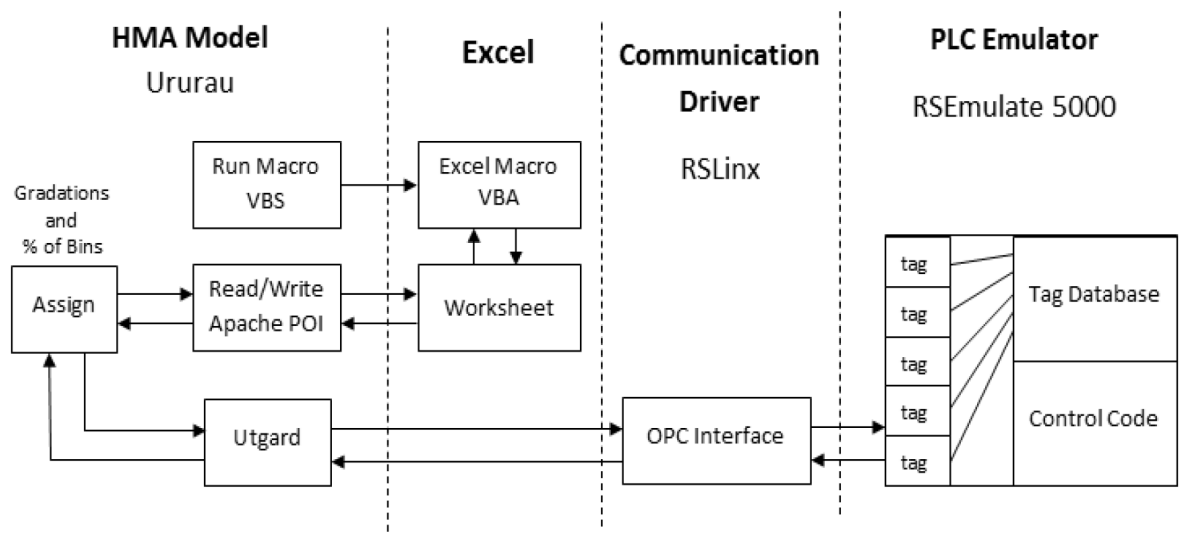

Figure 4 - Integration of simulation model, Ururau, Excel and PLC.

It was also developed a "Read/Write" block and a "Run Macro" block in the development environment of Ururau so that the user can read and write information in Excel cells and run macros in VBA (Visual Basic for Applications) code. Figure 5 represents these blocks.

The "Read/Write in Sheet" block is used to read values of the spreadsheet and store them as variable in Ururau or write Ururau variables in Excel cells. The user has to define the variable names, select if the variable will be read or written in Excel (if the box in the "Write to File?" column is unchecked, Ururau will be able to read the value of the cell and if it is checked, Ururau will be able to write in cell), define the cell in the spreadsheet that will be manipulated and inform 


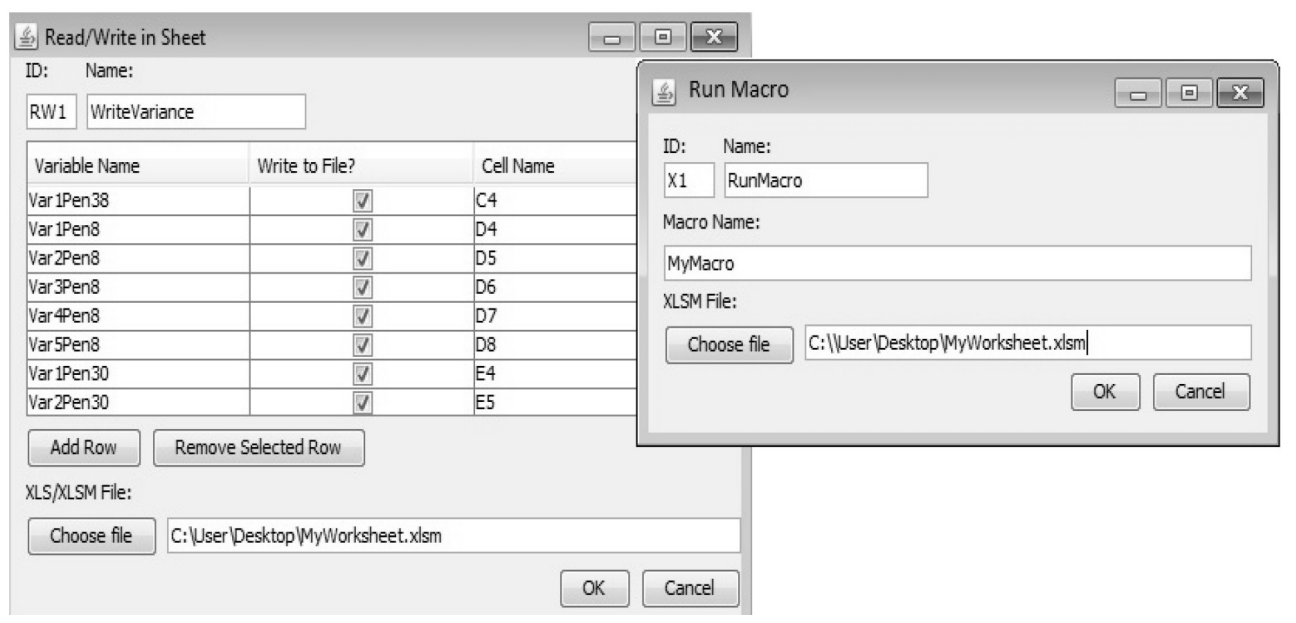

Figure 5 - Read/Write and Run Macro in Ururau Interface.

the path where the file is in the computer. In the "Run Macro", the user has to report the name of the macro developed in Excel and the path where the file is located in the computer.

Figure 4 also shows that in order that the VBA macros are run, a parameterized VBS (Visual Basic Script) code file was used, which is executed by Ururau in Java where it opens Excel, runs the desired macro and saves the file keeping the values updated.

The information of the simulation is sent to the PLC using the "Assign" block by the integration of Ururau with the OPC server with the OPC Utgard client. Available at (http:// openscada.org/projects/utgard). This OPC client is part of the OpenSCADA software; however, it can be used regardless of the platform. The Utgard is 100\% pure JAVA OPC Client API and Open Source.

It was used the Rockwell Automation RSEmulate 5000 emulator, which simulates the behavior of a real PLC and communicates with the Ururau by means of its OPC Communication Driver RsLinx.

\section{SIMULATION MODEL}

The construction of the simulation models followed the methodology proposed by Banks et al. (2010), in which the next steps were taken: formulation of the problem; definition of the objective and overall project plan; elaboration of the conceptual model; data collection; translation of the conceptual model; verification; validation; experimentation; execution and analysis. The verification and validation of the models also followed the steps suggested by Sargent (2013).

The simulation was used to vary the values of gradation of aggregates according to the system proposed, which allows testing and commissioning of the system with large economy and flexibility. Changing the parameters in the project can be very costly, and simulation permits the 
process to be tested using different scenarios, enabling adjustments in the control and deep analysis of the process. A Free Open Source Software (FOSS) for the DES called Ururau was used. Full description of the language used in Ururau is available at https://bitbucket.org/ururau/ururau (Peixoto, 2017).

The software was applied to generate the trend curves of the gradation of the aggregates, send information to Excel and communicate with the PLC (Programmable Logic Controller) and with the supervisory system.

The simulation can be followed in real time by the supervisory system developed in the Factory Talk View SE of Rockwell Automation Company, generating graphics in real time and enabling commands, such as Reset of counters. That is illustrated in Figure 6. All simulation parameters are described in Appendix A.

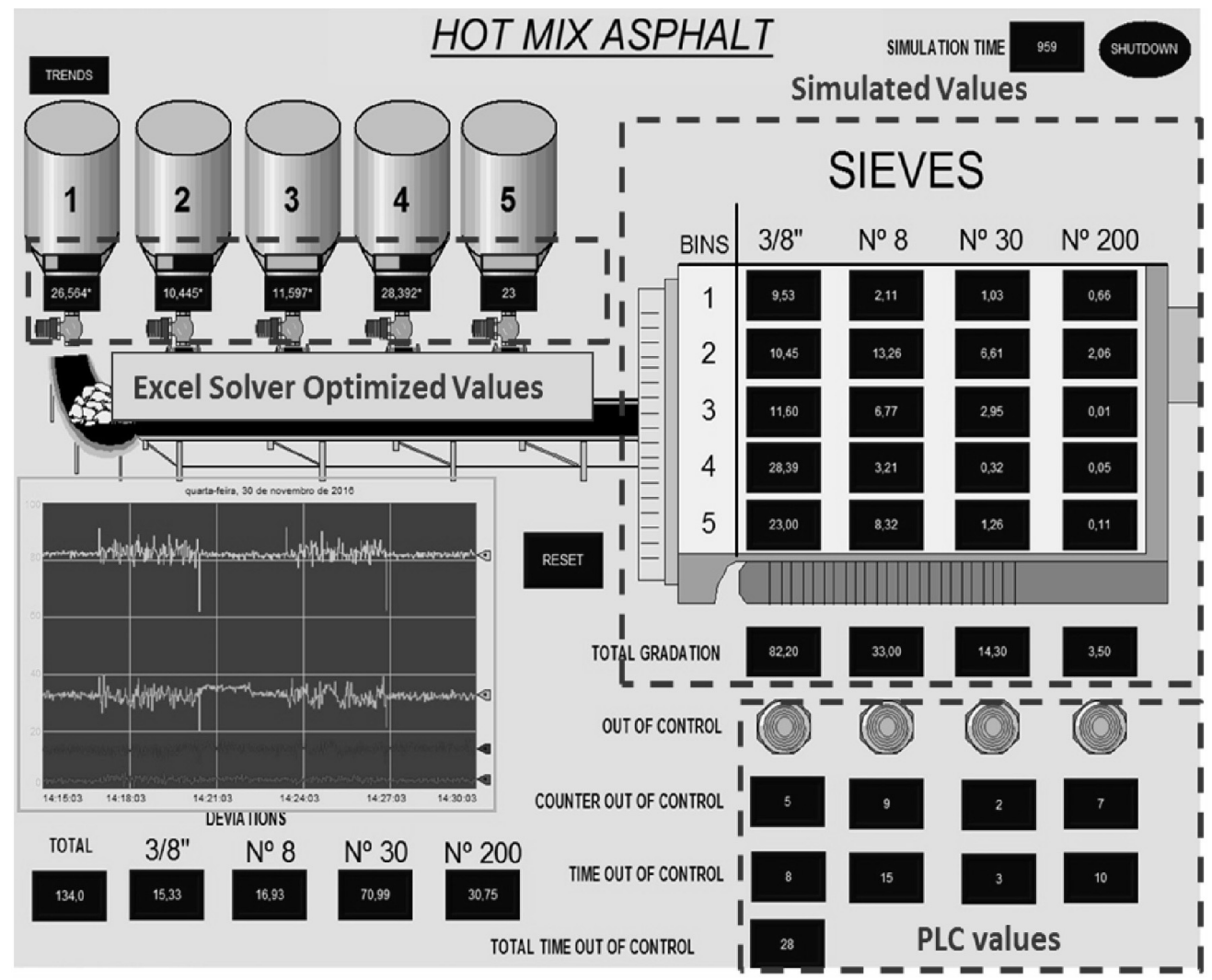

Figure 6 - Illustration of Human Machine Interface of Hot Mix Asphalt.

According to Figure 6, the simulated values are represented as individual values of gradation of cold-feed Bin in each sieve and can be visualized at the top right of the Figure. The total gradation values are also numerically represented. A graphic with these values is generated for the historical monitoring of the process behavior. Table 1 describes in details the respective values. 
When some sieve is out of control, the signal light "Out of control" will turn red. This indicator is controlled by the PLC with comparison blocks that monitor if the values are within the control parameters. As well as the "Counter out of control" counters (that count the number of times each sieve was out of control), the "Time out of control" (that count the time each sieve was out of control) and "Total Time out of control" (that counts the total time the system was out of control) are monitored in real time by the PLC. This information can be visualized at the bottom right of the Figure. The bar graphs with bin openings of each bin and their respective values are generated by the Solver optimization that calculates the optimal percentage of opening of each bin when the system is out of control and can also be visualized at the top left of the Figure.

The conceptual model of the system is based on the IDEF-SIM, which is a language used for the conceptual description of a simulation model, presented by Montevechi et al. (2010). Figure 7 represents the conceptual model used to simulate the Hot Mix Asphalt Production.

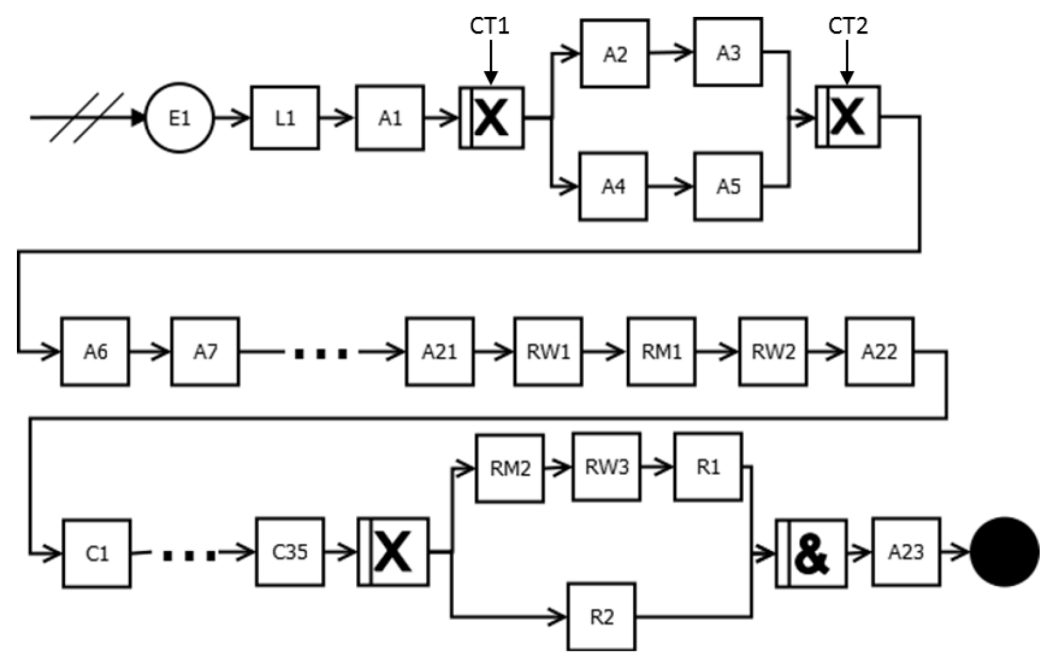

Figure 7 - Conceptual model in IDEF-SIM.

The element E1 (Create) creates entities every 1 minute in the simulation. The elements L1 (Hold), A1 (Assign) and A23 (Assign) form a set, in which the next entity created by the element E1 is only released after the previous entity has passed by all elements of the simulation. That is, the entities pass through the simulation elements, one at a time. The structure of OR, A2, A3, A4 and A5 (Assigns) is used to generate a trend function that describes a possible change in aggregate gradation over time. The trend function applied in the work is the alternating step function, according to Figure 8.

The trend function increases and decreases by $33.33 \%$ the variables over time around its mean in the interval of every two hours simulated during the entire simulation. The elements from A6 to A21 (Assigns) generate the normal curves of each aggregate gradation multiplied by the trend function. The RW1 (Read/Write in Excel) element writes the values of aggregate gradation generated in Excel. The RM1 (Run Macro in Excel) activates the macro that will update the 


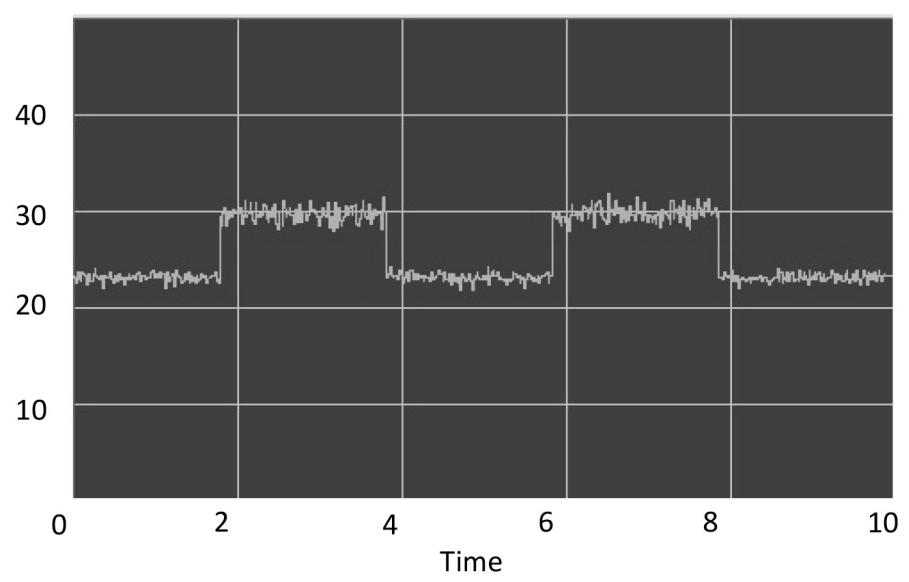

Figure 8 - Alternating step Function.

calculations of the Excel, and then the RW2 will read the updated and calculated values of the spreadsheet.

The A22 has the function of totalizing the sieves deviation. Structure C1 up to C35 has the function of communicating all needed values with the PLC. The OR, RM2, RW3, R1, and R2 structure has the function of verifying whether there is any sieve out of control. If there is one or more out of control, then the RM2 will activate the Solver that will calculate the proportions of Bin openings to optimize the mixture. These values are read from Excel by the element RW3, and the R1 will count how many times the mixture was optimized. The R2 element counts how many times the mixture was under control and optimization was not necessary.

\section{INPUT DATA AND PARAMETERS}

At the same time, the model works with a spreadsheet in a MS Excel file. In this file, there are the inputs of the simulation models. Zhang (2014) reported that The U.S. National Center for Asphalt Technology provides the input data for testing the system. These data are commonly observed in operations of asphalt plants and specifications and limits of typical mixture projects.

The data consist of three parts (according to Tables 1 and 2). The first part is the mean and pattern deviation of the granulation of each sieve for the five silos. A process simplification will only consider the most influent sieves instead of all eight sieves that are commonly used. The four most influent sieves are 3/8", No.8, No.30 and No.200. The values of mean and standard deviation of the sieve granulation are expressed in material percentage that will pass by each of them and are shown at the top of Table 1. The second part is the Mixing Process and the upper and lower tolerance limits for each specification or production, which are presented in the last lines of Table 1 and indicate tolerance values for more or less $( \pm)$ acceptable of the goal of Mixing Project. 
Table 1 - The Aggregate Input Data and Specifications (Zhang, 2014).

\begin{tabular}{l|c|c|c|c|c}
\hline \multirow{2}{*}{ Aggregate criteria } & \multirow{3}{*}{ Bins } & \multicolumn{4}{|c}{ Sieves } \\
\cline { 3 - 6 } & & $3 / 8 ”$ & Number & Number & Number \\
& 1 & 52 & 14 & 7.9 & 3.7 \\
\hline \multirow{3}{*}{ Mean of gradation } & 2 & 100 & 96 & 51 & 14 \\
& 3 & 100 & 86 & 41 & 1.4 \\
& 4 & 100 & 7 & 1 & 0.1 \\
& 5 & 100 & 52 & 9 & 0.7 \\
\hline \multirow{3}{*}{ Standard deviation of gradation } & 1 & 3.00 & 2.00 & 1.00 & 1.00 \\
& 2 & 0.00 & 1.00 & 4.00 & 2.00 \\
& 3 & 0.00 & 2.00 & 3.00 & 0.50 \\
& 4 & 0.00 & 1.00 & 0.50 & 0.50 \\
JMF sieves target percentage & 5 & 0.00 & 3.00 & 2.00 & 0.01 \\
\hline Specification limit tolerance & & 82.20 & 33.00 & 14.30 & 3.50 \\
Product limit tolerance & & 8.00 & 5.00 & 4.00 & 2.00 \\
\hline
\end{tabular}

The initial percentages of the Mixing Project and the upper and lower limits of the five silos of cold inputs are demonstrated in Table 2. The percentage of each silo during the production has to be within its upper and lower limits, and this restricts the procedure of process optimization.

Table 2 - The Aggregate Initial Data and Limits (Zhang, 2014).

\begin{tabular}{c|c|c|c}
\hline \multirow{2}{*}{ Bin } & \multirow{2}{*}{ Initial proportion } & \multicolumn{2}{|c}{ Bin capacity range percentage } \\
\cline { 3 - 4 } & & Minimum & Maximum \\
\hline 1 & 37 & 17 & 57 \\
2 & 14 & 5 & 23 \\
3 & 7 & 2 & 12 \\
4 & 30 & 10 & 50 \\
5 & 12 & 5 & 23 \\
\hline
\end{tabular}

\section{OPTIMIZATION MODEL}

When the system is out of control, the optimization process is initiated. The data of the process simulated by the Ururau are sent to an Excel spreadsheet, and then the Solver is initiated to find the optimal solution for the system. The aim of the optimization is to minimize the total deviation between the mixture gradation and the gradation predicted in the Job Mix Formula in all sieves. 
All the restrictions of the process depend on the JMF required. The optimization algorithm was adapted from Kabadurmus et al. (2010) and is defined as follows:

$$
\begin{array}{ll}
\min & \sum_{j} D_{j}=\frac{\left|n_{j}-\sum_{i} x_{i} g_{i j}\right|}{\left(r_{j}^{\max }-r_{j}^{\min }\right) / 2} \\
\text { s.t.: } & s_{i}^{\max } \leq x_{i}=s_{i}^{\min } \\
& r_{j}^{\max } \leq \sum_{i} x_{i} g_{i j} \leq r_{j}^{\min } \\
& \sum_{i} x_{i}=1 \\
& x_{i} \geq 0
\end{array}
$$

where $i$ is each cold feed bins, $j$ is each sieves, $D j$ is the total deviation.

The decision variable of the model is:

- Weight percentage of the total mixture from the bins $\left(x_{i}\right)$.

The parameters are:

- Gradation measurements from bins $\left(g_{i j}\right)$;

- Target levels (by JMF) for \% passing the sieves $\left(n_{j}\right)$;

- Upper and lower limit of specification \% of passing through the sieves $\left(r_{j}^{\max }, r_{j}^{\min }\right)$;

- Upper and lower limit for \% of weigh coming from each silo $\left(s_{i}^{\max }, s_{i}^{\min }\right)$.

\section{COMPUTATIONAL EXPERIENCE AND RESULTS}

The simulation was tested in various scenarios, combining variations in input gradation and specification limits, comparing the process efficiency without the Solver and with the Solver optimization. The control limits applied are the Specification Limit Tolerance and Product Limit Tolerance, described in Table 1. When the product was out of these limits, they were considered out of control. Two cases for the variations in the input gradation were employed: Low Variation (described in Table 1) and High Variation (the values of Table 1 multiplied by 1.5). The results were obtained by a single simulation round equivalent to 10 hours (600 minutes) simulated, corresponding to one working day in a typical HMA production plant.

The results are in the HMI software generating graphics and showing the immediate values of the variables according to Figure 9.

As specified by Figure 9, the gradation values of each sieve can be historically observed by means of the graphics generated by the supervisory system. This resource allows observing the behavior of the system over time and all changes of Bin openings when the system is out of control. 


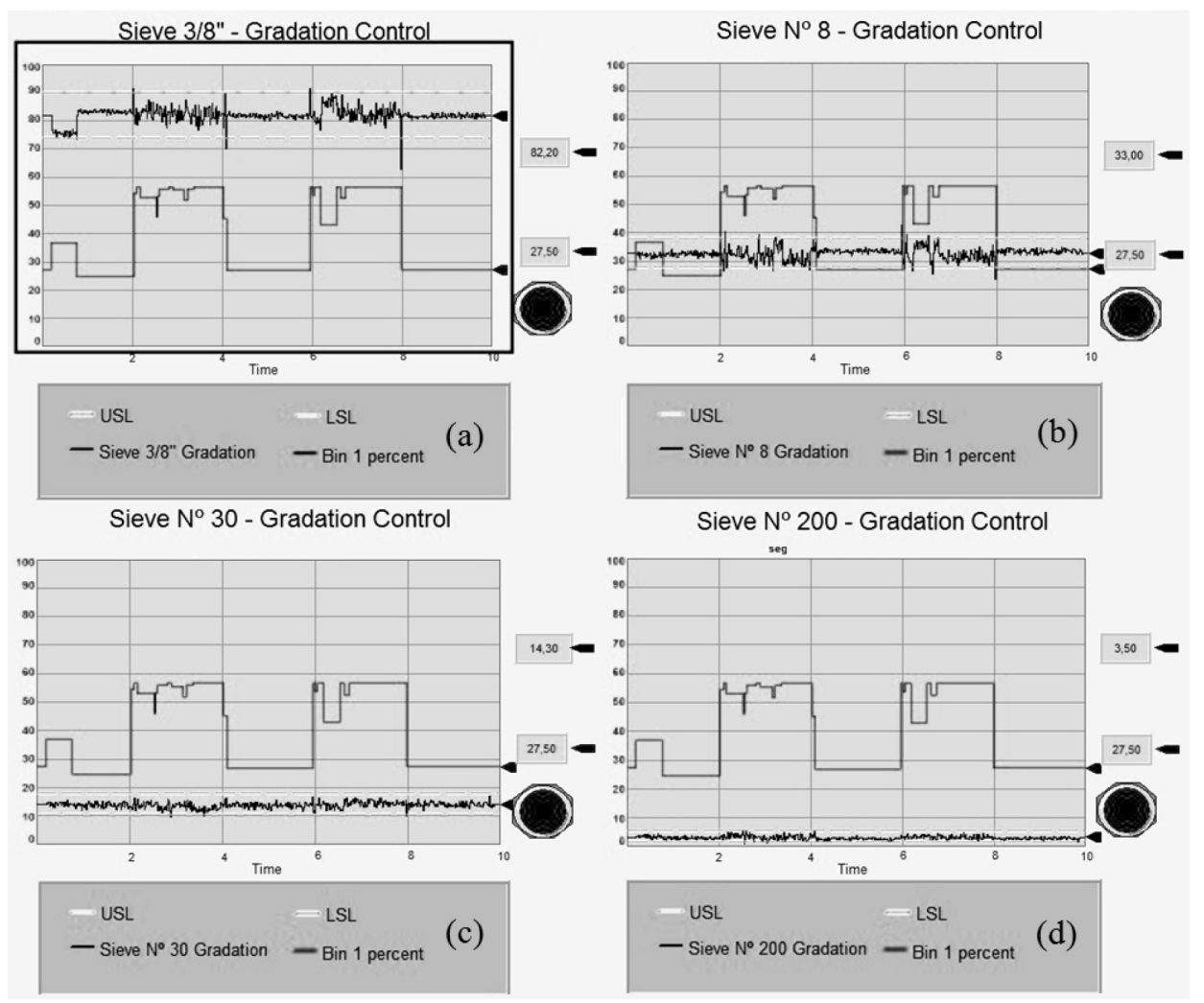

Figure 9 - Screen shot of simulation output for low variation solver control strategy: (a) gradation of sieve 3/8" from all bins (top) with bin 1 percentage of the mix (bottom); (b) gradation of sieve \#8 from all bins with bin 1 percentage of the mix; (c) gradation of sieve \#30 from all bins (bottom) with bin 1 percentage of the mix (top); (d) gradation of sieve \#200 from all bins (bottom) with bin 1 percentage of the mix (top).

It can also be seen the results by the report generated by the Ururau software that, at the end of the simulation round, creates a detailed report of the simulation and its variables. An example of a part of this report is in Figure 10.

Notice that, in Figure 10, the report presented by the Ururau software also has relevant information, such as the means of gradations of each sieve, total cumulative deviation and counters, which indicate how many times the Solver was initiated during the simulation. The analysis of the results is based on the time out of control and on the total cumulative deviation. The time out of control corresponds to how long the system, simulated in minutes, was out of the Control Limit when the maximum is 600 minutes (10 hours of simulation time). The Ururau software calculates the value of the total cumulative deviation. In every cycle of the simulation (every one minute simulated), the Ururau obtains the value of the sum of the deviation percentages of each sieve in relation to the JMF target (Equation 1) and totalizes it with the value of the previous cycle. 


\begin{tabular}{lrccrr}
\hline User Variables & mean & $\begin{array}{c}\text { standard } \\
\text { deviation }\end{array}$ & half-width & minimum & maximum \\
\hline GradSieve38 & 82.370 & $\mathrm{NaN}$ & $\mathrm{NaN}$ & 82.370 & 82.370 \\
GradSieve8 & 34.330 & $\mathrm{NaN}$ & $\mathrm{NaN}$ & 34.330 & 34.330 \\
GradSieve30 & 13.156 & $\mathrm{NaN}$ & $\mathrm{NaN}$ & 13.156 & 13.156 \\
GradSieve200 & 3.249 & $\mathrm{NaN}$ & $\mathrm{NaN}$ & 3.249 & 3.249 \\
TotalcumDeviation & 572.056 & $\mathrm{NaN}$ & $\mathrm{NaN}$ & 572.056 & 572.056 \\
\hline \hline Counters & mean & standard & half-width & minimum & maximum \\
& & deviation & & & \\
\hline R1 CounterSolver & 25.000 & NaN & NaN & 25.000 & 25.000 \\
R2 CounterOK & 576.000 & NaN & NaN & 576.000 & 576.000 \\
\hline
\end{tabular}

Figure 10 - Part of the report generated by Ururau.

The results are summarized in Table 3.

Table 3 - Results of Simulations.

\begin{tabular}{c|c|c|c|c|c}
\hline & & \multicolumn{2}{|c|}{ Control Strategy } & \multicolumn{2}{c}{$\%$ Reduction } \\
\hline $\begin{array}{c}\text { Control } \\
\text { Limit }\end{array}$ & $\begin{array}{c}\text { Aggregate } \\
\text { Variation }\end{array}$ & $\begin{array}{c}\text { No } \\
\text { Control }\end{array}$ & $\begin{array}{c}\text { Solver } \\
\text { Control }\end{array}$ & $\begin{array}{c}\text { Time } \\
\text { Out of } \\
\text { Control }\end{array}$ & $\begin{array}{c}\text { Total } \\
\text { Cumulative } \\
\text { Deviation }\end{array}$ \\
\hline SL & Low & $\begin{array}{c}31(0) \\
804.86\end{array}$ & $\begin{array}{c}25(25) \\
572.05\end{array}$ & 19.35 & 28.93 \\
\hline SL & High & $\begin{array}{c}70(0) \\
944.22\end{array}$ & $\begin{array}{c}63(67) \\
735.95\end{array}$ & 10.00 & 22.06 \\
\hline PL & Low & $\begin{array}{c}544(0) \\
1156.73\end{array}$ & $\begin{array}{c}40(39) \\
710.81\end{array}$ & 92.65 & 38.55 \\
\hline PL & High & $\begin{array}{c}502(0) \\
1313.23\end{array}$ & $\begin{array}{c}139(140) \\
934.62\end{array}$ & 72.31 & 28.83 \\
\hline
\end{tabular}

*\#time out of limits (\#mix changes). Total cumulative deviation from all sieves.

Note: SL (Specification Limit); PL (Product Limit).

According to Table 3, the optimization obtained a better result with the Production Limit Tolerance, which is more limited than the Specification Limit Tolerance, presenting an improvement of $92.65 \%$ in the time out of control when compared to No Control System Strategy. However, the optimization did not prove to be effective when the system presented a high variation in its input aggregates, in comparison with the system that has a lower variation, activating the solver more frequently and generating instabilities in the system.

In all situations tested, the optimization strategy with the solver presented a reduction both in the time out of control and in the total cumulative deviation. This result demonstrates the validity and the effectiveness of the system proposed. 


\section{CONCLUDING REMARKS}

This work describes a real time on-line control of dosing input aggregates for hot mix asphalt production. The free and open source discrete event simulation software Ururau was applied to simulate the process, exchange data and manipulate spreadsheets in the Excel software. The Solver was used to optimize the mixture in real time. One of the main difficulties in the dosing processes is the variety in its inputs and the capacity of rapidly identifying and correcting this deviation. The system presented proved to be effective in this correction during the production, guaranteeing a standardization and an increase of quality in the final product.

The application for hot mix asphalt process proved itself efficient; however, this principle may also be applied to other input dosing processes. Knowing the variables, curves, and restrictions of the processes, this system shows flexibility and safety as it allows logic tests, commissioning and adjustments in the control system, with no damage to the real system, besides the code of the Ururau software is open, enabling the user to adapt the software to his/her preference and carry out a series of tests.

The aim of this new simulation software is to disseminate, use and understand discrete event simulation in Brazil, allowing the users to be in contact with this specific software for simulation, developing his/her abilities and having the possibility to know the internal conception of the software structure.

\section{ACKNOWLEDGMENTS}

The authors thank the Coordination for the Improvement of Higher Education Personnel (CAPES), the National Council for Scientific and Technological Development (CNPq) and the Research Foundation of the State of Rio de Janeiro (FAPERJ) for financial support for this research. Thanks are also due to Maria Marta Garcia for assistance in translating the paper.

\section{REFERENCES}

[1] Banks J, Carson SJ, Nelson BL \& Nicol D. 2010. Discrete-event system simulation, (5 ed.). New York: Prentice Hall: Englewood Cliffs. 622 p.

[2] Christensen D. 2010. A mix design manual for Hot Mix Asphalt - Draft Report, National Cooperative Highway Research Program (NCHRP), National Academy of Sciences, Washington, D.C. Conference, 1522-1533.

[3] Fu MC, Andradottir S, Carson JS, Glover F, Harrell CR, Ho Y, Kelly JP \& RobinSON SM. 2000. Integrating optimization and simulation: Research and practice. In: Winter Simulation Conference Proceedings, 1: 610-616.

[4] Imole Oi, Krijgsman D, Weinhart T, Magnanimo V, Chávez Montes Be, Ramaioli M \& LUDING S. 2016. Experiments and discrete element simulation of the dosing of cohesive powders in a simplified geometry. In: Powder Technology, 287: 108-120.

[5] Jahangirian M, Eldabi T, Naseer A, Stergioulas LK \& Young T. 2010. Simulation in manufacturing and business: A review. European Journal of Operational Research, 203(1): 1-13.

[6] Kabadurmus O, Pathak O, Smith JS, Smith AE \& Yapicioglu H. 2010. A simulation methodology for online process control of hot mix asphalt (HMA) production. In: Winter Simulation Conference, 1522-1533. 
[7] Montevechi JaB, Leal A, Pinho A, Costa RF, Oliveira ML \& Silva Al. 2010. Conceptual modeling in simulation projects by mean adapted IDEF: An application in a Brazilian Company. In: Proceedings of the Winter Simulation Conference, edited by JoHANSSON B, JAIn S, MonToYatorRes J, HugAn J \& YÜCESAn E, 1624-1635. Piscataway, New Jersey: Institute of Electrical and Electronics Engineers, Inc.

[8] Oesterreich TD \& Teuteberg F. 2016. Understanding the implications of digitisation and automation in the context of Industry 4.0: A triangulation approach and elements of a research agenda for the construction industry. In: Computers in Industry, 83: 121-139.

[9] Peixoto TA, Rangel JJA, Matias IO, Silva FF \& Tavares ER. 2017. Ururau: a free and open-source discrete event simulation software. Journal of Simulation, 11: 303-321. [doi.org/10.1057/s41273-016-0038-5].

[10] SARgent RG. 2013. Verification and validation of simulation models. Journal of Simulation, 7(1): $12-24$.

[11] Schuh G, Reuter C, Hauptvogel A \& Dölle C. 2015. Hypotheses for a Theory of Production in the Context of Industry 4.0. In: Advances in Production Technology. Springer International Publishing. Lecture Notes in Production Engineering, p. 11-23. [DOI 10.1007/978-3-319-12304-2_2]

[12] Xu J, Huang E, Hsieh L, Lee LH, Jia Q \& Chen C. 2016. Simulation optimization in the era of Industrial 4.0 and the Industrial Internet. In: Int. J. Simulation and Process Modelling, 10(4): 310-320.

[13] Zhang M, Heitzman M \& Smith AE. 2014. Improving hot mix asphalt production using computer simulation and real time optimization. J. Comput. Civ. Eng., 2014.28. In: American Society of Civil Engineers (ASCE), p. 1-7 [DOI: 10.1061/(ASCE)CP.1943-5487.0000302].

Appendix A - Simulation parameters.

\begin{tabular}{c|l|l}
\hline Name & Function & Parameters \\
\hline E1 & Create & Constant $(1)$ min \\
\hline L1 & Hold & if Release $==0$ \\
\hline CT1 & OR & $\begin{array}{l}(\text { TNOW }<=120) \|((\mathrm{TNOW}>240) \\
\& \&(\mathrm{TNOW}<=360)) \|(\text { TNOW }>480)\end{array}$ \\
\hline A1 & Assign (Variable) & Release $==1$ \\
\hline A2 & Assign (Variable) & Function1 $==1.33$ \\
\hline A3 & Assign (Variable) & Function2 $==0.67$ \\
\hline A4 & Assign (Variable) & Function1 $==0.67$ \\
\hline A5 & Assign (Variable) & Function2 $==1.33$ \\
\hline CT2 & OR & $100 \%(U n i o n)$ \\
\hline A6 & Assign (Variable) & Var1Sieve38 $==$ Function2 $* \operatorname{NORM~}(52,3)$ \\
\hline A7 & Assign (Variable) & Var1Sieve8 $==$ Function2 $* \operatorname{NORM~}(14,2)$ \\
\hline A8 & Assign (Variable) & Var2Sieve8 $==$ Function1 $* \operatorname{NORM~}(96,1)$ \\
\hline A9 & Assign (Variable) & Var3Sieve8 $==$ Function2 $* \operatorname{NORM}(86,2)$ \\
\hline A10 & Assign (Variable) & Var4Sieve8 $==$ Function1 $* \operatorname{NORM}(7,1)$ \\
\hline
\end{tabular}


Appendix A - (continuation).

\begin{tabular}{|c|c|c|}
\hline Name & Function & Parameters \\
\hline A11 & Assign (Variable) & Var5Sieve $8==$ Function $2 * \operatorname{NORM}(52,3)$ \\
\hline $\mathrm{A} 12$ & Assign (Variable) & Var1Sieve30 == Function $2 * \operatorname{NORM}(7.9,1)$ \\
\hline $\mathrm{A} 13$ & Assign (Variable) & Var2Sieve $30==$ Function $1 * \operatorname{NORM}(51,4)$ \\
\hline A14 & Assign (Variable) & Var3Sieve $30==$ Function $2 * \operatorname{NORM}(41,3)$ \\
\hline A15 & Assign (Variable) & Var4Sieve $30==$ Function $1 * \operatorname{NORM}(1,0.5)$ \\
\hline A16 & Assign (Variable) & Var5Sieve30 == Function $2 * \operatorname{NORM}(9,2)$ \\
\hline A17 & Assign (Variable) & Var1Sieve200 == Function2*NORM $(3.7,1)$ \\
\hline A18 & Assign (Variable) & Var2Sieve200 == Function $1 * \operatorname{NORM}(14,2)$ \\
\hline A19 & Assign (Variable) & Var3Sieve200 == Function2*NORM $(1.4,0.5)$ \\
\hline A20 & Assign (Variable) & Var4Sieve200 == Function $1 * \operatorname{NORM}(0.1,0.05)$ \\
\hline A21 & Assign (Variable) & Var5Sieve200 == Function $2 * \operatorname{NORM}(0.7,0.01)$ \\
\hline RW1 & Read/Write in Excel & Write all sieves functions in Excel \\
\hline RM1 & Run Macro in Excel & VBA “Application.CalculateFull” \\
\hline RW2 & Read/Write in Excel & $\begin{array}{l}\text { Read Sieves Gradation, Deviations, } \\
\text { \# Sieve Out Specifications, \% Bin Openings }\end{array}$ \\
\hline A22 & Assign (Variable) & AcumDeviation $==$ AcumDeviation + TotalDeviation \\
\hline $\mathrm{C} 1$ & Communication (Real Tag) & BinOpen1 \\
\hline $\mathrm{C} 2$ & Communication (Real Tag) & BinOpen2 \\
\hline $\mathrm{C} 3$ & Communication (Real Tag) & BinOpen3 \\
\hline $\mathrm{C} 4$ & Communication (Real Tag) & BinOpen4 \\
\hline $\mathrm{C} 5$ & Communication (Real Tag) & BinOpen5 \\
\hline C6 & Communication (Real Tag) & AcumDeviation \\
\hline $\mathrm{C} 7$ & Communication (Real Tag) & Bin1Sieve38 \\
\hline $\mathrm{C} 8$ & Communication (Real Tag) & Bin2Sieve 38 \\
\hline C9 & Communication (Real Tag) & Bin3Sieve38 \\
\hline $\mathrm{C} 10$ & Communication (Real Tag) & Bin4Sieve38 \\
\hline $\mathrm{C} 11$ & Communication (Real Tag) & Bin5Sieve38 \\
\hline $\mathrm{C} 12$ & Communication (Real Tag) & GradationSieve38 \\
\hline $\mathrm{C} 13$ & Communication (Real Tag) & DeviationSieve38 \\
\hline $\mathrm{C} 14$ & Communication (Real Tag) & Bin1Sieve8 \\
\hline $\mathrm{C} 15$ & Communication (Real Tag) & Bin2Sieve8 \\
\hline $\mathrm{C} 16$ & Communication (Real Tag) & Bin3Sieve8 \\
\hline $\mathrm{C} 17$ & Communication (Real Tag) & Bin4Sieve8 \\
\hline $\mathrm{C} 18$ & Communication (Real Tag) & Bin5Sieve8 \\
\hline $\mathrm{C} 19$ & Communication (Real Tag) & GradationSieve8 \\
\hline $\mathrm{C} 20$ & Communication (Real Tag) & DeviationSieve8 \\
\hline
\end{tabular}


Appendix A - (continuation).

\begin{tabular}{c|l|l}
\hline Name & Function & Parameters \\
\hline C21 & Communication (Real Tag) & Bin1Sieve30 \\
\hline C22 & Communication (Real Tag) & Bin2Sieve30 \\
\hline C23 & Communication (Real Tag) & Bin3Sieve30 \\
\hline C24 & Communication (Real Tag) & Bin4Sieve30 \\
\hline C25 & Communication (Real Tag) & Bin5Sieve30 \\
\hline C26 & Communication (Real Tag) & GradationSieve30 \\
\hline C27 & Communication (Real Tag) & DeviationSieve30 \\
\hline C28 & Communication (Real Tag) & Bin1Sieve200 \\
\hline C29 & Communication (Real Tag) & Bin2Sieve200 \\
\hline C30 & Communication (Real Tag) & Bin3Sieve200 \\
\hline C31 & Communication (Real Tag) & Bin4Sieve200 \\
\hline C32 & Communication (Real Tag) & Bin5Sieve200 \\
\hline C33 & Communication (Real Tag) & GradationSieve200 \\
\hline C34 & Communication (Real Tag) & DeviationSieve200 \\
\hline C35 & Communication (Real Tag) & TotalDeviation \\
\hline OR2 & OR & \# Sieve Out Specifications >=1 \\
\hline RM2 & Run Macro in Excel & VBA “SolverSolve(True)" \\
\hline RW3 & Read/Write in Excel & Read Sieves Gradation, Deviations, \\
& & \# Sieve Out Specifications, \% Bin Openings \\
\hline R1 & Counter & CounterSolver == CounterSolver + 1 \\
\hline R2 & Counter & ReunterOK == CounterOK + 1 \\
\hline A23 & Assign (Variable) & \\
\hline
\end{tabular}

